doi.org/I0.51891/rease.v7i2.666

\title{
A EDUCAÇÃO SOCIAL COMO INSTRUMENTO DE HUMANIZAÇÃO PARA APRENDIZAGEM NO PROGRAMA DE CAPACITAÇÃO PROFISSIONAL
}

\author{
SOCIAL EDUCATION AS A HUMANIZATION INSTRUMENT FOR \\ LEARNING IN THE PROFESSIONAL TRAINING PROGRAM
}

\author{
Artur Alves Farias Júnior ${ }^{1}$ \\ Ruth Sales Gama de Andrade ${ }^{2}$
}

\begin{abstract}
RESUMO: Dentro da proposta pedagógica da Sala de Extensão PROPEX, ligada à PróReitoria de Pesquisa e Extensão (PROPEX), no Campus Aracaju, do Instituto Federal de Sergipe (IFS), desde o início de 2016, a multidisciplinaridade é ferramenta fundamental para o enriquecimento da formação acadêmica e cidadã da comunidade interna e externa da instituição. Para a programação de 2017, o Programa de Capacitação Profissional (PCP) surge como leitura mais subjetiva e humanizada, baseando-se no tripé: segurança do trabalho, meio ambiente e saúde e, ainda, em conceitos de Educação Social para suporte da metodologia dos cursos oferecidos. Como opções, têm-se os cursos de NR 20 / Frentista de Postos Combustíveis e de Atendente de Farmácia. Deste modo, vê-se o PCP não só como um conjunto de cursos profissionalizantes, mas também como facilitador de aprendizagem ao propor conexões com temas cidadãos para o empoderamento do indivíduo e assim melhor prepará-lo para o mercado de trabalho. Nessa perspectiva, o presente trabalho propõe possibilitar a conexão do caráter reprodutivista de ensino de cursos de capacitação com o olhar humanizado, ao entendê-los como agentes transformadores na comunidade. Para nortear o estudo, além de conceitos literários, consideraram-se informações do Estatuto da Criança e do Adolescente (ECA), Organização das Nações Unidas para Educação, Ciência e Cultura (Unesco), Ministério do Desenvolvimento Social (MDS/BR) e aplicação de questionário com estudantes atendidos, de modo a demonstrar a evolução do programa.
\end{abstract}

Palavras-chave: Educação Social. Capacitação. Aprendizagem.

ABSTRACT: Within the pedagogical proposal of the PROPEX Extension Room, linked to the Dean of Research and Extension (PROPEX), at the Aracaju Campus, of the Federal Institute of Sergipe (IFS), since the beginning of 2016, multidisciplinarity is a fundamental tool for enrichment academic and citizen education of the institution's internal and external community. For the 2017 schedule, the Professional Training Program (PCP) emerges as a more subjective and humanized reading, based on the tripod: work safety, environment and health, and also on Social Education concepts to support the methodology of courses offered. As options, there are the NR 20 / Gas Station Attendant and Pharmacy Attendant courses. In this way, the PCP is seen not only as a set of professional courses, but also as a learning facilitator by proposing connections with citizen themes for the empowerment of the individual and thus better preparing him for the job market. In this perspective, the present

\footnotetext{
${ }^{1}$ Educador, Especialista em Segurança do Trabalho e Gestão Ambiental (UCAM), Aracaju/SE. E-mail: arturfarias.aju@hotmail.com.

²Educadora, doutora em Química (UFSCar), Aracaju/SE.E-mail: ruth.sales@ifs.edu.br.
} 
work proposes to make it possible to connect the reproductive character of teaching training courses with a humanized perspective, by understanding them as transforming agents in the community. To guide the study, in addition to literary concepts, information from the Statute of Children and Adolescents (ECA), United Nations Educational, Scientific and Cultural Organization (Unesco), Ministry of Social Development (MDS / BR) and application questionnaire with students attended, in order to demonstrate the evolution of the program.

Keywords: Social Education. Training. Learning.

\section{INTRODUÇÃO}

O entendimento que observa a Educação Social é multidisciplinar e contribui efetivamente para a atenção à subjetividade que há em cada indivíduo, quais suas necessidades e em qual nicho ele ou ela pode se inserir na sociedade. É também, uma intervenção socioeducativa para a comunidade, sobretudo para grupos em situação de maior vulnerabilidade, onde o educador é peça fundamental, para o contato com a comunidade e na criação de mecanismos de socialização que, além de capacitar para o mercado de trabalho, contribuam com a sua formação cidadã. Sendo essa, baseada no processo de diálogo presente no que Paulo Freire (1974) chamou de educação como prática da liberdade, “[...] É o momento em que se realiza a investigação do que chamamos de universo temático do povo ou o conjunto de seus temas geradores".

Em "O desenvolvimento do psiquismo", Leontiev (1978) definiu homem e mulher

como um "ser social" e tudo o que tem de humano nele e nela provém da vida em sociedade. Portanto, é a partir da apropriação da cultura e da formação educacional que estes se transformam e transformam a natureza. Nesse sentido, se humanizam e a escola se coloca como instrumento de promoção na conquista da cidadania, ou seja, a partir da "assimilação ativa dos conteúdos" (LIBÂNEO, 2008).

Apesar de ao longo dos anos a democratização do acesso à educação integrar as reivindicações de variados setores sociais, essa se intensificou a partir de meados de 1980, resultando na aprovação do princípio de gestão democrática na educação, na Constituição Federal art. 206. A Constituição Federal/88 estabeleceu princípios para a educação brasileira, dentre eles: obrigatoriedade, gratuidade, liberdade, igualdade e gestão democrática, sendo esses regulamentados através de leis complementares. Enquanto lei complementar, a Lei de Diretrizes e Bases da Educação Nacional (LDB n.o 9.394/96) observa e regulamenta as diretrizes gerais para a educação e seus respectivos sistemas de ensino. Em cumprimento ao art. 214 da Constituição Federal, ela dispõe ainda acerca do Plano Nacional de Educação - PNE (art. 9.ํ), resguardando os princípios constitucionais e, inclusive, de gestão democrática. 
Termos como "administração da educação" ou "gestão da educação" são comumente utilizados ora como sinônimos, ora como termos distinguidos. "Analisar a gestão da educação, seja ela desenvolvida na escola ou no sistema municipal de ensino, implica em refletir sobre as políticas de educação. Isto porque há uma ligação muito forte entre elas, pois a gestão transforma metas e objetivos educacionais em ações, dando concretude às direções traçadas pelas políticas" (BORDIGNON; GRACINDO, 200o, p. 147). Para a gestão, quando entendida como processo de um sistema político-administrativo, é estabelecido o desafio não só de contextualizar esse modelo, mas também de compreendê-lo enquanto processo educativo a partir dos conceitos de sistemas de gestão escolar. Tal modelo de gestão implica normativas, bem como sua vinculação jurídica entre instituições sociais através de diretrizes comuns, como resguarda a LDB, no Programa Nacional de Fortalecimento dos Conselhos Escolares:

A democratização dos sistemas de ensino e da escola implica aprendizado e vivência do exercício de participação e de tomadas de decisão. Trata-se de um processo a ser construído coletivamente, que considera a especificidade e a possibilidade histórica e cultural de cada sistema de ensino: municipal, distrital, estadual ou federal de cada escola.

A partir desse entendimento emergem, em um horizonte amplo, as possibilidades do profissional educador social realizar o seu trabalho, de forma mais humanizada e menos meramente reprodutivista. Nessa perspectiva e cumprindo o seu papel formador para a comunidade do IFS, a Sala de Extensão PROPEX tem o Programa de Capacitação Profissional, como um importante transmissor e promotor de conhecimentos, além de ser agente mediador e incentivador do processo de conquista da cidadania.

\section{Educação social}

O modelo desenvolvimentista adotado a partir do século XVIII, com a Revolução Industrial na Inglaterra, impulsionou as desigualdades sociais enquanto ampliou, em proporção aritmética, a exclusão de grande parcela da sociedade, com os chamados proletários, deficientes das necessidades mais básicas. Processo este, que ao longo dos anos, constrói diversas lacunas nas esferas econômicas, sociais, educativas e culturais. Embora, desde a Idade Média existisse uma tendência ao caráter extracurricular da pedagogia, e que teóricos como Froebel e Pestalozzi reconhecessem a necessidade de contemplar a questão humanitária, filosófica e política, foi somente após a segunda revolução industrial, no século XIX, que a grande exclusão social e crise econômica favoreceram na Inglaterra e em outras nações europeias, uma necessidade de inclusão social mais intensa e que contemplasse a multidão que surgia. 
No mesmo século, duas nações despontaram em programas sociais de caráter sócio educativo: Alemanha e Espanha, onde a primeira pode ser considerada percursora da chamada pedagogia social, graças aos trabalhos de Adolph Diesterweg. Já Henryk Goldszmit (1878 1942), importante pediatra e pedagogo, atuou na II Guerra Mundial acolhendo órfãos em abrigos e orfanatos e deixando textos de significativa importância para desenhar o que chamamos hoje de educação social, tornando-se inclusive, o percursor dos Direitos da Criança.

No início do século XX, a pedagogia social surge no Brasil com ênfase no assistencialismo das políticas públicas. Mais tarde, na década de 6o, Paulo Freire, criou a educação para adultos e começou a implementar a multidisciplinaridade como instrumento de trabalho para contribuir com a formação social e educacional do indivíduo. Sendo este, o escopo da Educação Social, oficializada na década de 7o, em Portugal, inicialmente como curso técnico profissionalizante e equivalente ao $12 . .^{\mathrm{O}}$ ano da escolaridade. Curiosamente, Paulo Freire é uma das referências sempre presentes na Pedagogia Social forjada na Europa e na América Latina, apesar de nunca ter utilizado este termo em seus escritos, [...] especialmente pela vertente da Educação Popular que ele consagrou (SILVA, NETO e MOURA, 2009).

No Brasil da década de 8o, em meio às diversas mudanças políticas e sociais, os profissionais que atuavam junto à infância e adolescência começaram a passar por um processo de formação que observava, na maioria das vezes, "[...] proporcionar articulação entre educação e as demais políticas sociais e organizações do terceiro setor, estabelecendo parcerias, facilitando o acesso da comunidade escolar aos seus direitos" (MARTINS, 1999, p. 6o).

Desse modo, tem-se na educação social o desdobramento de outras terminologias, que se adequaram ao longo dos anos, tais como: educação não formal, informal e popular, já que é por meio da educação, mas não só por ela, que se pode contribuir para a garantia de direitos. Em contrapartida, a pedagogia social, ainda que sirva de base para a educação social, diferenciase, sobretudo, no fato de a última não se basear no assistencialismo, mas sim na justiça social e formação cidadã do sujeito excluído, como disserta Resende (2006):

[...]a educação social existe porque a exclusão existe. Seja em programas de assistência ou naqueles em que se busca a formação cidadã, a base para sua existência encontra-se na exclusão característica do modo de produção capitalista e na lógica da competição que o sustenta.

Cada uma das particularidades enfrentadas pela comunidade precisa receber um tipo de atenção diferenciada e, além disso, suas potencialidades também devem servir para organização de serviços que estimulem a participação social. Todos os serviços de convivência e fortalecimento de vínculos (SCFV) organizam-se em torno do Serviço de Proteção e Atenção Integral à Família - PAIF (decreto n.ำ 5085/2004), atualizado em 2015, de modo que 
previnam a segregação de crianças, adolescentes, jovens e idosos, conforme explica o Ministério do Desenvolvimento Social (MDS/BR):

São prioridades as seguintes situações consideradas de maior vulnerabilidade social: famílias vivendo em nulo ou frágil acesso à saúde, à educação e aos demais, em especial, famílias monoparentais, chefiadas por mulheres, com filhos ou dependentes; famílias provenientes de outras regióes, sem núcleo familiar, com restrita rede social; famílias retiradas de seu local de origem, em função da implementação de empreendimentos com impacto ambientais e sociais; Famílias pertencentes aos povos e comunidades tradicionais (indígenas, quilombolas, ciganos e outros); Famílias ou indivíduos com vivência de discriminação (étnico-raciais e culturais, etárias, de gênero, por orientação sexual, por deficiência e outras) (...).

Há ainda o Estatuto da Criança e do Adolescente (Lei 8069/90) como eixo legal para orientação nas ações de atendimento, pois determina a existência de uma rede de atenção, e esta deve ser absorvida de modo que o educador conheça a rede social do seu ambiente de trabalho, de seu município ou região, bem como suas interligações. Este é o educador social, segundo Silva, Neto e Moura (2009):

Educador social serve no Brasil, tanto para identificar o trabalhador de nível médio e técnico como para designar o trabalhador com formação de nível superior em desvio de função. Oficineiros, artesãos, artistas, mestres de capoeira, arte-educadores e monitores em geral são agregados a uma mesma categoria descritiva, [...] contratados por organizações privadas, não-governamentais ou pelo poder público $[\ldots]$.

\section{Metodologia}

Com a evidente importância da multidisciplinaridade e dando continuidade ao trabalho de atendimento à inclusão da Sala de Extensão PROPEX, no Campus Aracaju, do Instituto Federal de Sergipe, o Programa de Capacitação Profissional sustenta-se na educação social e no tripé: Segurança do Trabalho, Meio Ambiente e Saúde (SMS), o que possibilita a conexão do caráter reprodutivista de ensino de cursos de capacitação com o olhar humanizado, ao entendê-los como agentes transformadores na comunidade.

O cenário do atendimento do Programa de Educação de Jovens e Adultos (PROEJA) que, por sua vez, em sua maioria, é o público-alvo do PCP, apresenta, de modo geral, estudantes em situação de vulnerabilidade social, onde se percebe o necessário suporte da figura do educador social. Ainda que as práticas e reflexões deste profissional sejam pouco estudadas, busca-se neste trabalho refletir sobre a atuação dos conceitos de educação social para o processo de humanização para aprendizagem no Programa de Capacitação Profissional, na instituição. Este programa foi escolhido pelo fato de seu atendimento apresentar muitas 
expectativas em relação às suas atividades e a Sala de Extensão PROPEX representar um espaço significativo no projeto pedagógico do IFS.

Dentro desse paradigma, propõe-se a conexão do caráter reprodutivista de ensino de cursos de capacitação já conhecidos, como os de NR 20 / Frentista de Postos Combustíveis e de Atendente de Farmácia, com o olhar humanizado, ao entendê-los como agentes transformadores na comunidade. Deste modo, o trabalho volta-se a compreender as concepções dos estudantes, especificamente os atendidos pelo PCP, em relação às capacitações desenvolvidas, às conexões estabelecidas com temas cidadãos e as relações entre esse programa e as classes populares.

A pesquisa foi qualitativa e a multirreferencialidade auxiliou na constituição teórica, propondo-se a "uma leitura plural (de seus objetos); a partir de diferentes ângulos; em função de sistemas de referências distintos (o transbordamento-magma do objeto); não redutíveis uns aos outros (supostos, reconhecidos), ou seja, heterogêneos" (BORBA, 1998, p. 12). Os procedimentos realizados foram entrevistas pré-estruturadas com o público atendido, em dia comum de aula, com intuito de compreender as suas vozes a respeito das práticas propostas pelo programa.

Ainda sobre o estudo da metodologia, é necessário aprender como se comportar em uma entrevista, decifrar o uso das linguagens não verbais de determinadas regiões, a linguagem correta a ser usada para uma entrevista, o respeito a cultura local, como elaborar questionários e fazer a leitura destes, estudar primeiramente o local a ser feito a pesquisa e entender os comportamentos da comunidade em estudo. É sabido que todo projeto de pesquisa que se propõe a trabalhar com seres humanos apresenta implicações éticas que necessitam serem discutidas e adequadas para sua execução e para se cumprir com as determinações éticas previstas é necessário observar rigorosamente as recomendações contidas na Resolução n. 466/12 (BRASIL, 2013).

Segundo esta Resolução, vigente em todo o país, pesquisa envolvendo seres humanos é aquela que "individual ou coletivamente, envolva o ser humano, diretamente ou indireta, em sua totalidade ou parte dele, incluindo o manejo de informações ou materiais”. Desta forma, os procedimentos incluem, entre outros, os de natureza instrumental, ambiental, nutricional, educacional, sociológica, econômica, física, psíquica ou biológica, sejam eles farmacológicos, clínicos ou cirúrgicos e de finalidade preventiva, diagnóstica ou terapêutica (BRASIL, 2013). A pesquisa envolvendo seres humanos deverá prever procedimentos que assegurem a confidencialidade e a privacidade dos indivíduos pesquisados, garantindo a proteção da sua imagem, a sua não estigmatização e a não utilização das informações em prejuízo dos 
indivíduos e/ou das comunidades, inclusive em termos de autoestima, de caráter econômico e/ou financeiro (VIEIRA, 2003).

\section{Resultados e Discussões}

A partir da aplicação do questionário para uma amostra de estudantes atendidos pelo PCP, em dia comum de aula, durante o mês de maio, é possível discutir aspectos encontrados em relação às capacitações desenvolvidas. Em primeiro, identifica-se um total de 26 estudantes entrevistados, onde destes: $\mathrm{I} 2$ se declaram homens e 14 mulheres; faixa etária compreendida entre 16 e 40 anos, onde I8 pertencem ao PROEJA, 6 ao Ensino Médio, 2 à Graduação. Do total de entrevistados, observa-se ainda que io pertencem à comunidade externa e, ainda, que dos I8 que declararam estar desempregados, II são homens e 7 são mulheres. Em seguida, através de múltipla escolha, é possível discutir diferentes aspectos, conforme demonstram os gráficos:

Gráfico I - Você já participou de alguma capacitação antes deste programa?

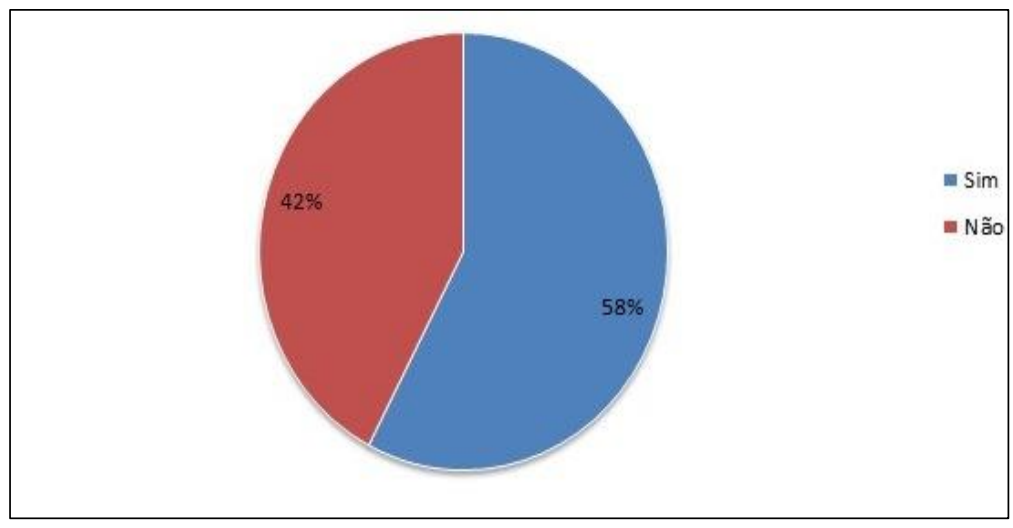

Gráfico 2 - Aulas semanais ajudam na inclusão do programa junto à comunidade?

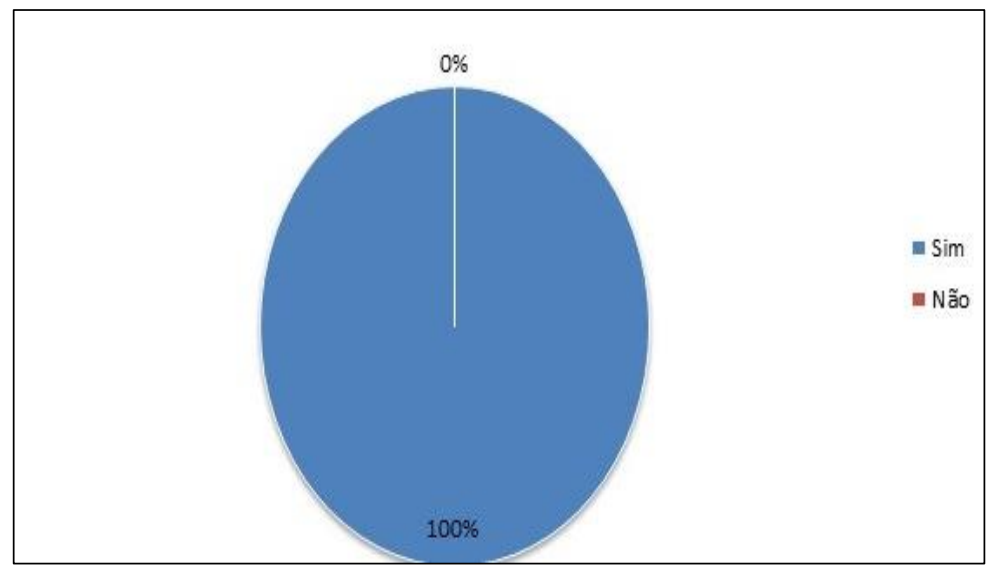


Gráfico 3 - Como você avalia o grau de importância do Programa de Capacitação Profissional para a comunidade?

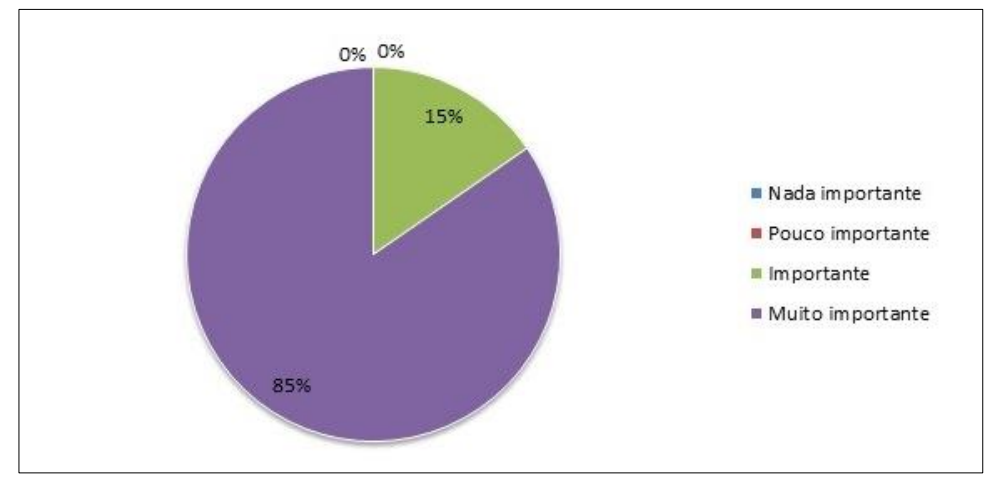

Gráfico 4 - Como você avalia o grau de importância do Programa de Capacitação Profissional para o mercado de trabalho:

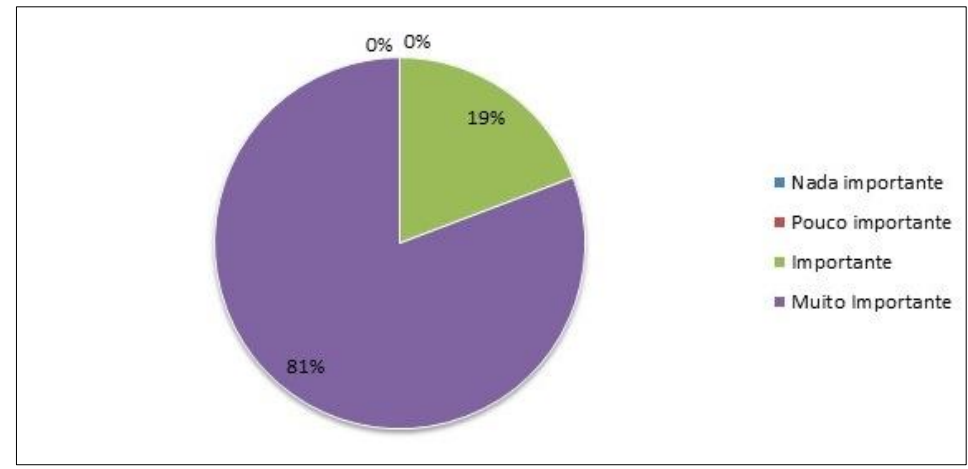

Gráfico 5 - Como você avalia a importância da abordagem de temas cidadãos para conectar com os assuntos da capacitação?

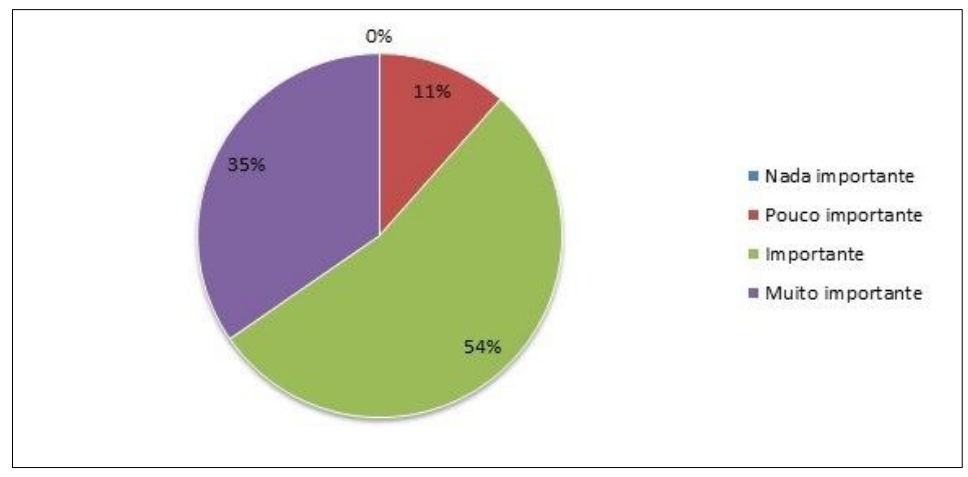


Gráfico 6 - Escolha três temas que você considera importantes para serem discutidos durante os cursos do programa:

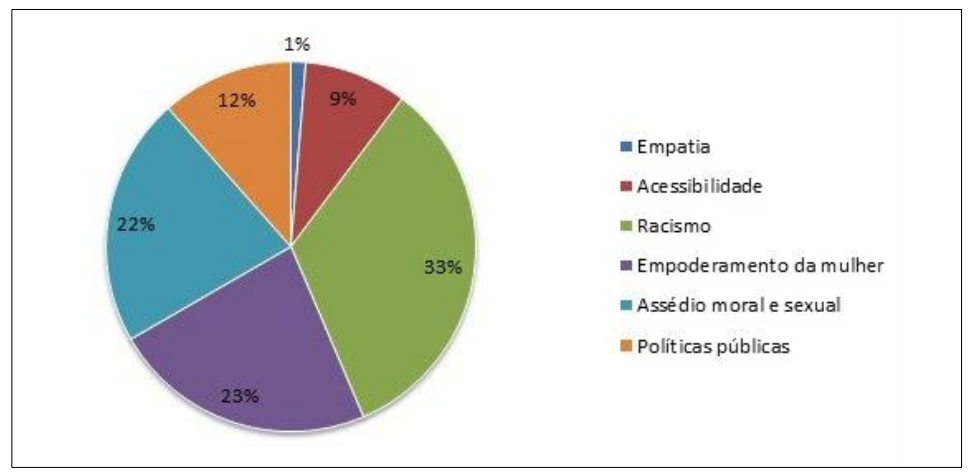

Através dos gráficos I, 3 e 4, percebe-se que a comunidade já possuía o entendimento da necessidade de participação em cursos de capacitação, ainda que uma parcela expressiva não tivesse tal vivência. Observa-se ainda um contra ponto interessante, quando, ao invés de aulas diárias, o que diminuiria o prazo para finalização dos cursos, a modalidade semanal é preferida pela totalidade de entrevistados e entrevistadas, conforme demonstra o gráfico 2. Chama atenção que $89 \%$ consideram importante ou muito importante tratar sobre temas cidadãos durante os cursos, ratificando a importância das conexões entre o programa e esses temas.

Esses resultados demonstram a boa receptividade dos estudantes para trabalhar questões de representatividade, visibilidade e, sobretudo, cidadania. Conforme o gráfico 6, o temário mais expressivo: racismo, assédio moral e sexual e empoderamento da mulher, atesta a evolução do diálogo sobre minorias sociais - negros e mulheres, neste caso - quando fica visível o acolhimento à necessidade de melhor entendimento de questões ligadas às parcelas de maior vulnerabilidade na sociedade, as quais esses temas se referem. Em suma, somar esforços para garantir o acolhimento de todos é contribuir para que as individualidades sejam melhor representadas e isso cria um panorama interessante para a ampliação de discussões, estudos e pesquisas correlatas.

\section{Referências}

FREIRE, P. Pedagogia da autonomia: saberes necessários à prática educativa. São Paulo: Paz e Terra. 1997

FREIRE, P. Pedagogia do Oprimido. São Paulo: Paz e Terra. 1974

LEONTIEV, Alexis. O Desenvolvimento do Psiquismo. Lisboa: Horizonte. 1978. p. 261-284

LIBÂNEO, José Carlos. Didática. São Paulo: Cortez. 2008

BORDIGNON, G.; GRACINDO, R.V. Gestão da Educação: o município e a escola. In: FERREIRA, N. S. C.; AGUIAR, M. A. da S. (Org.), Gestão democrática da educação: impasses, perspectivas e compromissos. São Paulo: Cortez, 20oo. p. 147 
BRASIL. Estatuto da Criança e do Adolescente, lei 8069/9o. Porto Alegre: CRESS, 2000

BRASIL. Ministério da Educação. Secretaria de Educação Básica. Programa Nacional de Fortalecimento dos Conselhos Escolares. Gestão da educação escolar. Brasília: UnB, CEAD, 2004, vol. 5. p. 25

MEC/BR. Lei de Diretrizes e Bases da Educação Nacional, nº 9394/1996

MDS/BR. Serviço de Proteção e Apoio Integral à Família, nº 5085/2004

FRIGOTTO, G. A Produtividade da Escola Improdutiva 30 anos depois: Regressão e Hegemonia às avessas. Trabalho Necessário, 2015, n. 20, p. 206

FRIGOTTO, G. Educação e a crise do capitalismo real. 4 ed. São Paulo: Cortez, 20oo, p. 26

MARTINS, Eliana Bolorino Canteiro. O Serviço Social na área da Educação. In: Revista Serviço Social \& Realidade. v.8. n r. UNESP, Franca: São Paulo, 1999

RESENDE, Marlene. Exclusão e educação social: conceitos em superfície e fundo. Educ. Soc., Campinas, n. 94, 2006

SILVA, Roberto da, NETO, João Clemente de Souza, MOURA, Rogério Adolfo. Pedagogia Social. São Paulo: Expressão e Arte Editora, 2009

NATALI, Paula Marçal. O Lúdico em instituições de Educação não-formal: cenários de múltiplos desafios, impasses e contradições. Dissertação de Mestrado em Educação - Ponta Grossa 2009

CNS-MS/BR. Comitê de Ética em Pesquisa, resolução 466/2012

BORBA, Sérgio da Costa. Aspectos do conceito de multirreferencialidade nas ciências e nos espaços de formação. In: BARBOSA, Joaquim (org.). Reflexões em torno da abordagem multirreferencial. São Carlos: EdUFSCar. 1998

VIEIRA, V. A.. Hipertensão arterial e aspectos éticos em pesquisa envolvendo seres humanos: implicações para a área da saúde. Revista Brasileira de Saúde Materno Infantil, Recife, v.3, n.4, p.48I-488, out/dez, 2003 